Dhaka Univ. J. Sci. 60(2): 175-180, 2012 (July)

\title{
Removal of Arsenic from Ground Water with Shrimp Shell
}

\author{
Mohammad Arifur Rahman, Mohammad Motahar Hossain, Abdus Samad and A. M. Shafiqul Alam* \\ Department of Chemistry, University of Dhaka, Dhaka-1000, Bangladesh \\ E-mail:amsalam2010@gmail.com; marahman76@yahoo.com
}

Received on 15. 05. 2011. Accepted for Publication on 11. 01. 2012.

\begin{abstract}
A single arsenic decontamination system has been developed using shrimp shell for tube well water with arsenic concentration of $120 \mu \mathrm{g} / \mathrm{L}$ which could be lowered to $15 \mu \mathrm{g} / \mathrm{L}$. Arsenic was removed by this system from water by adsorption through fine particles of shrimp shell. Various conditions of adsorption/desorption of arsenic were investigated. Adsorption column method showed the complete removal of As(III) under the following conditions: initial As concentration, $100 \mu \mathrm{g} / \mathrm{L}$, amount of shrimp shell $3.0 \mathrm{~g}$, particle size $<355 \mu \mathrm{m}$, treatment flow rate $0.5 \mathrm{~mL} / \mathrm{min}$ and $\mathrm{pH}$ 6.5. Desorption efficiency was found in the range of $81-83 \%$ with $4 \mathrm{M}$ of $\mathrm{NaOH}$ after the treatment of groundwater. A combination of techniques was used to remove nine metals of groundwater. Other inorganic constituents of health concern $(\mathrm{Cu}, \mathrm{Cd}, \mathrm{Mn}$ and $\mathrm{Fe})$ in treated water were below their respective WHO guideline for drinking water.
\end{abstract}

Key words: arsenic, removal, shrimp shell, low cost, adsorption

\section{Introduction}

Arsenic (As) contamination in water has raised grave concerns in many regions of the world. It is widely distributed in the environment. Natural processes including soil erosion, mineral leaching and weathering are responsible for introducing arsenic into surface waters ${ }^{1}$. Industrial activities, such as mining and smelting of metal ores, combustion of fossil fuels, use of arsenical pesticides and waste effluents from manufacturing have resulted in the contamination of air, soils, and surface waters by arsenic compounds ${ }^{2}$. Arsenic occurs as organic and inorganic compounds in natural water. It is found that arsenic toxicity depends on its oxidation state. Arsenites are more toxic for biological systems as compared to arsenates. The toxicity of organic-arsenic compounds is lower as compared to inorganic forms of arsenic ${ }^{3}$.

The arsenic calamity of Bangladesh can be described as the largest known mass poisoning in the history, with an estimated 35-77 million people exposed to arseniccontaminated drinking water ${ }^{4}$. Arsenic contamination has been reported in groundwater in 61 out of the 64 districts in Bangladesh. About $61 \%$ of the tube wells have arsenic content above $0.05 \mathrm{mg} / \mathrm{L}$ and about $13 \%$ have arsenic content above $10 \mu \mathrm{g} / \mathrm{L}^{5}$. This is significantly higher than the World Health Organization (WHO) maximum permissible limit in drinking water $(50 \mu \mathrm{g} / \mathrm{L})$ and the recommended value is $10 \mu \mathrm{g} / \mathrm{L}$.

Arsenic can be removed from aqueous solution by using many technologies such as ion exchange resin, activated alumina, coprecipitation with iron or alum, reverse osmosis, membrane filtration, modified coagulation/filtration, and enhanced lime softening ${ }^{6,7}$. Among these methods, the adsorption techniques are simple and convenient and have the potential for regeneration and sludge free operation. Various adsorbents for arsenic removal have been evaluated, such as metal-loaded coral limestone, hematite and feldspar activated carbon activated alumina and hydrous zirconium oxide. Use of these chemicals as adsorbent causes secondary waste problem. However, majority of these methods are unsuitable for Bangladesh in consideration of efficiency and cost. Recently chitin has been recognized as an excellent sorbent for arsenic or heavy metals. However, the processes of producing chitin require large amount of acid and base. Chitin is one of the major constituent of shrimpshell which can be used directly to remove arsenic from aqueous solution.

Bangladesh is a shrimp exporting country. It is the third largest export item of Bangladesh. Hotels and restaurants use shrimp to prepare delicate food items. They dismantle the shell from shrimp and discard them as the municipal waste. Use of this shrimp shell as adsorbent might be a promising solution for arsenic removal from ground water of Bangladesh. It could also increase the additional value of shrimp byproducts.

The present work was performed to evaluate the use of waste shrimp shell without any chemical pretreatment as an alternate adsorbent for removing arsenite and arsenate from aqueous medium.

\section{Materials and Methods}

\section{Reagents}

All reagents used throughout this work were of analyticalgrade purity. Arsenic(III) standard solution of $1000 \mathrm{mg} / \mathrm{L}$ was procured from Aldrich and $\mathrm{NaOH}, \mathrm{KOH}, \mathrm{HCl}, \mathrm{HNO}_{3}$ and $\mathrm{H}_{2} \mathrm{SO}_{4}$ were obtained from Mark, Germany. Stock solution $(100 \mu \mathrm{g} / \mathrm{L})$ of $\mathrm{As}(\mathrm{III})$ was prepared in de-ionized water from Arsenic(III) standard solution of $1000 \mathrm{mg} / \mathrm{L}$. Dilute standard solutions were prepared daily before use.

\section{Adsorbent}

Shrimp shell was used as adsorbent. One of the major components of shrimp shell is chitin which constitutes 16-20\% of raw shrimp shell and may be regarded as cellulose with

*Author for correspondence 
hydroxyl group at second carbon position replaced by an acetamido group ${ }^{8}$. Chitin is a very good adsorbent since it hold many desired properties for sorbent materials such as biodegradable and cost effective ${ }^{9}$.

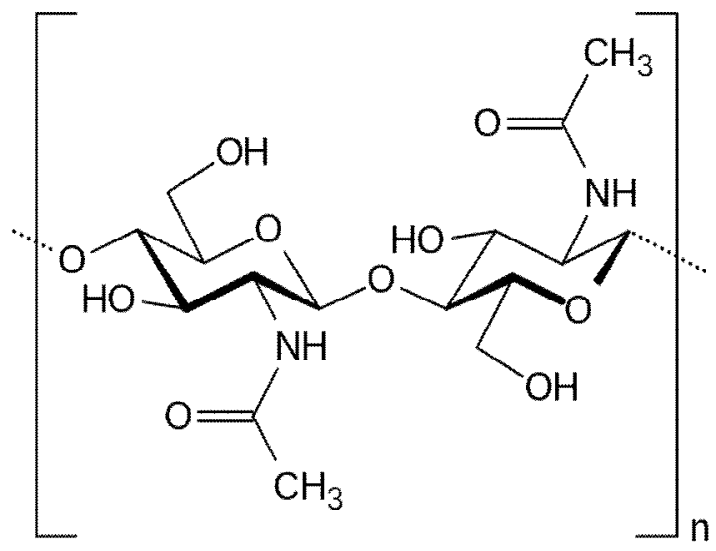

Fig. 1. Structure of chitin in Shrimp shell.

\section{Preparation of adsorbents}

The shrimp shell used in the present work was obtained from a local Chinese restaurant which is a common waste material in all restaurants and hotels in Bangladesh and even all over the world. It was washed thoroughly with pure water several times. The washed materials were then dried in a hot-air oven (NDO-450ND, EYELA, Japan) at $60{ }^{\circ} \mathrm{C}$ for 2 hours and $40{ }^{\circ} \mathrm{C}$ for 20 hours ${ }^{10}$. They were then grinded and sieved into three fractions such as (600425) $\mu \mathrm{m},(425-355) \mu \mathrm{m}$ and $<355 \mu \mathrm{m}$.

\section{Arsenic adsorption experiments in column}

The adsorption experiments were carried out in columns that were equipped with a stopper for controlling the column elution flow rate (treatment rate). A weighted amount of shrimp shell was added to the glass column (2 $\times 30 \mathrm{~cm}$ ). After adjustment of $\mathrm{pH}$ to the desired value with microvolume of $\mathrm{HCl}$ and $\mathrm{NaOH}$ solutions, the sample solution $(100 \mathrm{~mL})$ was passed through the adsorption column at a given flow rate. The aqueous solution was kept 20 minutes standing to facilitate the adsorption of arsenic by fine particles. The treatment flow rates of $0.5,3.0$ and $6.0 \mathrm{~mL} / \mathrm{min}$. The packing density of the treatment column was $0.60 \mathrm{~g} / \mathrm{cm}^{3}$. A small piece of glass wool was inserted into the bottom of the column to prevent the loss of adsorbent during the treatment. The flow rate was kept constant by controlling the stopper valve. Flow Injection Atomic Absorption Spectrophotometer (FIAS, Perkin Elmer, Analyst 800) was used for the determination of arsenic concentration. The removal (adsorption) efficiency was calculated using the following equation.

Removal (adsorption) efficiency $=\left(\mathrm{C}_{0}-\mathrm{C}_{\mathrm{e}}\right) / \mathrm{C}_{0} \times 100$

Where, $\mathrm{C}_{0}$ and $\mathrm{C}_{\mathrm{e}}$ are the concentration of As in the sample solution before and after treatment, respectively.

\section{Results and Discussion}

The performances of four adsorbents (shrimp shell, rice straw, tea leaves, and sawdust) were evaluated for the removal of As(III). Preliminary studies showed that complete removal of As(III) was achieved under the following conditions: initial concentration, $100 \mu \mathrm{g} / \mathrm{L}$; amount of shrimp shell $3.0 \mathrm{~g}$, treatment flow rates $0.5 \mathrm{~mL} / \mathrm{min}$ and particle size $<355 \mu \mathrm{m}$. Lower efficiency was found for other adsorbents and as a result shrimp sell was chosen to demonstrate as an effective adsorbent for the removal of As(III) from drinking water.

\section{Effect of Particle Size}

Column adsorption experiments were carried out for the removal of arsenic from aqueous solution using three different particle sizes $[<355 \mu \mathrm{m},(355-425) \mu \mathrm{m}$ and (425-625) $\mu \mathrm{m}]$ with different weight of adsorbent. The results are shown in Fig. 2. Highest $91 \%$ arsenic was removed with $3.0 \mathrm{~g}$ of shrimp shell of particle size $<355 \mu \mathrm{m}$. From the results, it is clear that lower the particle size, higher the adsorption efficiency. These phenomena might be due to the fact that the smaller particles offer comparatively larger surface areas and greater numbers of adsorption sites.

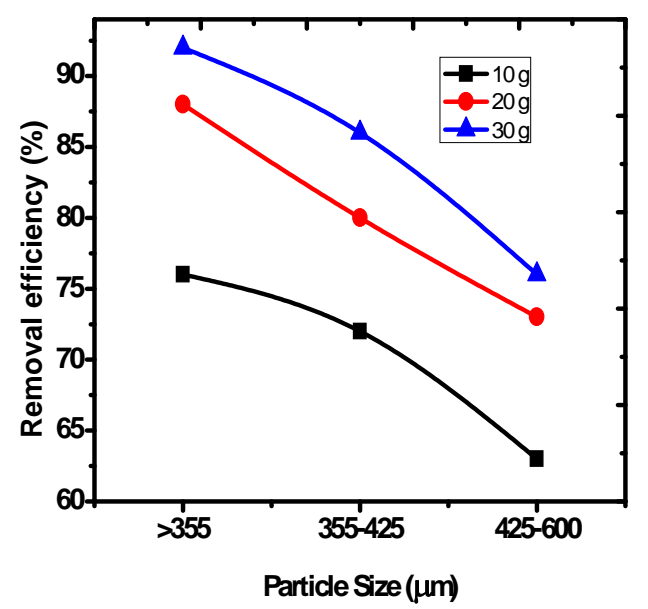

Fig. 2. Effect of particle size on the removal of As(III) by adsorption onto shrimp shell. Initial As concentration: $100 \mu \mathrm{g} / \mathrm{L}$; Treatment flow rate: $0.5 \mathrm{~mL} / \mathrm{min}$. 


\section{Effect of Adsorbent's Amount}

The effect of the amount of shrimp shell on the removal of As(III) was examined. Results are presented in Fig. 3. It shows that removal efficiency increases with increasing amount of adsorbent.

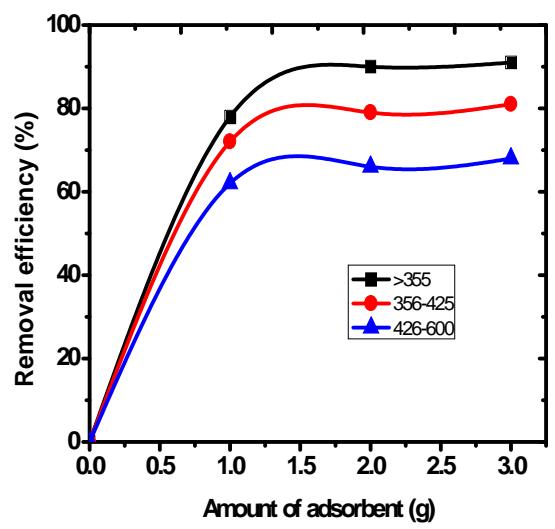

Fig. 3. Effect of adsorbent amount on the removal of As(III) by adsorption onto Shrimp shell. Initial As concentration: 100 $\mu \mathrm{g} / \mathrm{L}$; Particle size: $<355 \mu \mathrm{m}$; Flow rate: $0.5 \mathrm{~mL} / \mathrm{min}$

It is understood that the adsorption capacity of shrimp shell depends on the surface activity, that is, the specific surface area available for As-surface interactions. With increasing amount of shrimp shell ( $1.0 \mathrm{~g}$ to $3.0 \mathrm{~g})$ removal capacity $(76.39 \%$ to $91.47 \%$ ) is also increased.

\section{Effect of Flow Rate}

The effect of flow rate on the removal of $\mathrm{As}$ (III) is presented in Fig. 4. It is found that, the removal efficiency decreases with increasing flow rate. This is because, when the flow rate is slow, As(III) in the sample solution get more contact time with the active surface of the adsorbent shrimp shell. From these experiments, it is clear that highest removal efficiency is achieved with lower flow rate.

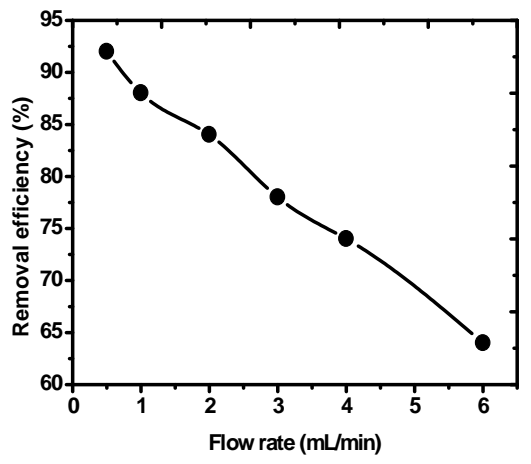

Fig. 4. Effect of flow rate on the removal of $\mathrm{As}(\mathrm{III})$ by adsorption onto shrimp shell. Initial As concentration: 100 $\mu \mathrm{g} / \mathrm{L}$; Amount of shrimp shell: $3.0 \mathrm{~g}$; Particle size: $<355 \mu \mathrm{m}$; Flow rate: $0.5 \mathrm{~mL} / \mathrm{min}$

\section{Effect of Initial Concentration}

The removal efficiency is highly dependent on the initial concentration of $\mathrm{As}(\mathrm{III})$ in the sample solution. The initial concentration was evaluated in the range of $50-500 \mu \mathrm{g} / \mathrm{L}$ and the results are presented in Fig. 5. The removal efficiency decreased with increasing the adsorbate concentration in the solution. At low concentration, most of the As(III) in the solution get enough active sites of sorbent but with increase of concentration, all As(III) species are not able to come in contact with active sites of sorbents. Therefore, arsenic removal efficiency is decreased.

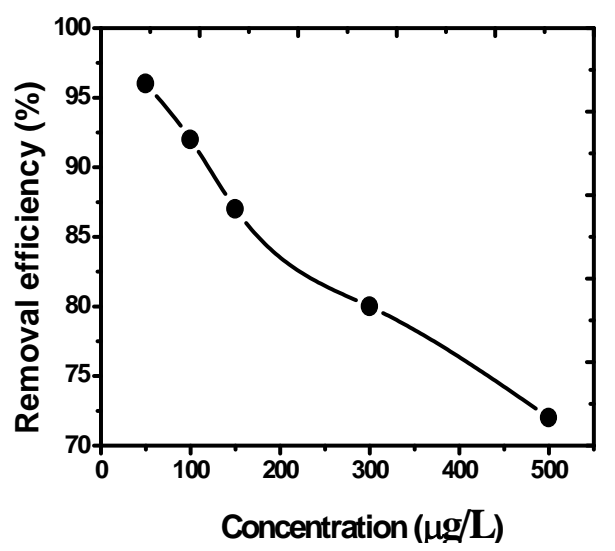

Fig. 5. Effect of initial adsorbate concentration on the removal of As(III) adsorption onto shrimp shell. Amount of shrimp shell: $3.0 \mathrm{~g}$; Particle size: $<355 \mu \mathrm{m}$; Flow rate: $0.5 \mathrm{~mL} / \mathrm{min}$

\section{Effect of Volume}

The effect of adsorbate volume on the removal of As(III) is shown in Fig. 6. It is observed that with increasing the volume the removal efficiency decreases. About $95 \%$ arsenic is removed when the volume is $50 \mathrm{~mL}$. At lower volume of arsenic solution, most of arsenic might get available adsorbent sites.



Fig. 6. Effect of initial adsorbate volume on the removal of As(III) by adsorption onto shrimp shell; Amount of shrimp shell: $3.0 \mathrm{~g}$; Particle size: $<355 \mu \mathrm{m}$. Flow rate: $0.5 \mathrm{~mL} / \mathrm{min}$ 


\section{Effect of pH}

$\mathrm{pH}$ is one of the most important parameters which control the metal ion sorption process ${ }^{11}$. Fig. 7 depicts the effect of $\mathrm{pH}$ on $\mathrm{As}$ (III) removal with shrimp shell. For the removal of As(III) the efficiency curve is pyramidal in the $\mathrm{pH}$ range of $4-10$.

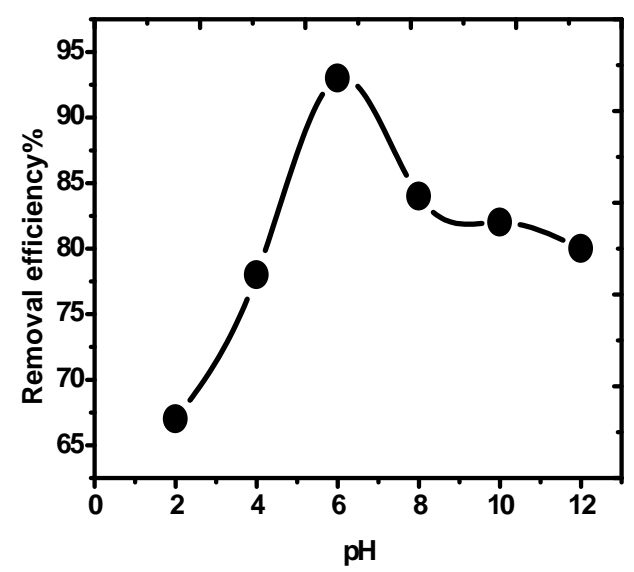

Fig. 7. Effect of $\mathrm{pH}$ on the removal of As(III) by adsorption onto shrimp shell. Initial As concentration: 100 $\mu \mathrm{g} / \mathrm{L}$; Amount of shrimp shell: $3.0 \mathrm{~g}$; Particle size:

$<355 \mu \mathrm{m}$; Flow rate $0.5 \mathrm{~mL} / \mathrm{min}$.

Highest removal efficiency is observed at $\mathrm{pH}$ 6. At low $\mathrm{pH}$ chitin in shrimp shell undergo degradation to smaller chain and become soluble in aqueous solution. At $\mathrm{pH}>$ 6 , the poor removal efficiencies are observed. At higher $\mathrm{pH}$, the net surface charge on the adsorbent becomes less positive. At $\mathrm{pH}>\mathrm{pH}_{\mathrm{zpc}}$ (6.3), the net surface charge becomes negative, resulting in repulsive forces between adsorbent and anionic adsorbate. The chemical species of $\mathrm{As}(\mathrm{III})$ in this $\mathrm{pH}$ region are oxoanions.

\section{Desorption of Sorbent and Recycling}

Recovery of the adsorbed material and regeneration of the adsorbent are also important aspects of wastewater treatment.

Attempts were made to desorb As(III) from the shrimp shell surface with various eluting agents, such as hydrochloric, sulfuric, nitric acid, sodium hydroxide and potassium hydroxide solutions. This desorption process was performed using the batch method. The results are presented in Table 1. It shows that effective desorption is obtained with alkaline solutions. Desorption of As(III) is very poor in the acidic media. In fact, the addition of acid into shrimp shell causes self degradation. As a result, acid desorption is not feasible. These phenomena are consistent with the results observed for the effect of $\mathrm{pH}$.
Table. 1. Influence of the Eluting agents on the Desorption of $\operatorname{As}$ (III)

\begin{tabular}{ccc}
\hline $\begin{array}{c}\text { Desorption } \\
\text { agent }\end{array}$ & Standing time & Desorption (\%) \\
\hline $\mathrm{NaOH}$ & 20 min & 59 \\
$(1 \mathrm{M})$ & I hour & 64 \\
& 2 hour & 65 \\
& 4 hour & 67 \\
& 8 hour & 68 \\
\hline $\mathrm{NaOH}$ & 20 min & 72 \\
$(2 \mathrm{M})$ & 1 hour & 75 \\
& 2 hour & 76 \\
& 8 hour & 80 \\
$\mathrm{NaOH}$ & 20 min & 83 \\
$(4 \mathrm{M})$ & 2 hour & 83 \\
$\mathrm{HCl}(1 \mathrm{M})$ & 4 hour & Degradation of \\
& 8 min & Shrimpshell \\
\hline
\end{tabular}

\section{Application of the Optimized Treatment System}

The utility of the waste shrimp shell was evaluated for the treatment of As contaminated groundwater samples in Bangladesh under optimized conditions. As the $\mathrm{pH}$ of these groundwater samples was around 7 , the arsenic species might be $\mathrm{HAsO}_{4}{ }^{2-}$ for $\mathrm{As}(\mathrm{V})$ and $\mathrm{H}_{3} \mathrm{AsO}_{3}$ for $\mathrm{As}(\mathrm{III})^{12}$. The treatment results are presented in Tables 2 and 3. The concentration of total arsenic in the studied samples was $120.28 \mu \mathrm{g} / \mathrm{L}$. About $80 \%$ arsenic desorption efficiency was achieved with $100 \mathrm{~mL}$ of $4 \mathrm{M} \mathrm{NaOH}$ solution. Present results indicate that arsenic as well as other metals is successfully removed from Ascontaminated groundwater, and the adsorbed arsenic could be recovered from the surface of shrimp shell.

\section{Arsenic Removal Mechanisms}

Shrimp shell contains chitin which is mainly responsible for arsenic adsorption. The high nitrogen and hydroxy content of chitin make up a large number of active sites that are subjected to different chemical interactions in water solutions. The free amino group $\left(-\mathrm{NH}_{2}\right)$ in chitosan exists in equilibrium with the protonated amino group in acidic aqueous solution.

$$
\mathrm{R}-\mathrm{NH}_{2}+\mathrm{H}^{+} \rightleftharpoons \mathrm{R}-\mathrm{NH}_{3}^{+}
$$

Chitosan with positive charge shows greater tendency to adsorb anions. Gao et al. ${ }^{13}$ reported that chitosan adsorbed anionic species quantitatively as oxoanions or chloro complex anions of metals in sample solution by an ion-exchange mechanism. This means that the interaction between $\mathrm{NH}_{3}{ }^{+}$in chitosan and anionic species of the arsenic is chiefly electrostatic. Arsenite speciation in an aqueous medium at $\mathrm{pH} \quad 3-11$ is controlled by $\mathrm{H}_{3} \mathrm{AsO}_{3}{ }^{\circ} \rightleftharpoons$ $\mathrm{H}_{3} \mathrm{AsO}_{3}{ }^{-}+\mathrm{H}^{+} ; p \mathrm{~K}_{\mathrm{a}}=9.2^{14}$. At $\mathrm{pH} 4$, the predominat arsenite species present in aqueous medium is uncharged $\mathrm{H}_{3} \mathrm{AsO}_{3}$, which cannot undergo electrostatic interaction with the chitosan. However, such species can interact with the unprotonated amino groups $^{15}$. Some hydroxyl groups in the adsorbent may be involved in coordination with the adsorbate. 
Table. 2. Removal of As from the contaminated Ground water by the optimizedmethod

\begin{tabular}{cccccc}
\hline No. of Analysis & $\mathbf{p H}$ & $\begin{array}{c}\text { Initial As concentration } \\
(\mu \mathrm{g} / \mathrm{L})\end{array}$ & $\begin{array}{c}\text { Final As concentration } \\
(\boldsymbol{\mu} \mathbf{g} / \mathbf{L})\end{array}$ & Removal (\%) & Desorption (\%) \\
\hline 1 & 7.49 & $120.28 \pm 2.3$ & $15.00 \pm 0.8$ & $87.50 \pm 1.5$ & $81 \pm 3.0$ \\
2 & 7.50 & $120.20 \pm 2.8$ & $15.12 \pm 0.9$ & $87.40 \pm 1.9$ & $80 \pm 2.8$ \\
3 & 7.45 & $118.42 \pm 2.1$ & $15.20 \pm 0.5$ & $87.00 \pm 1.6$ & $81 \pm 2.5$ \\
\hline
\end{tabular}

Amount of shrimp shell: $3.0 \mathrm{~g}$; particle size: $<355 \mu \mathrm{m}$; flow rate: $0.5 \mathrm{~mL} / \mathrm{min} ; \mathrm{pH}: \sim 7$

Table. 3. Average Concentration of major cations and anions of non-treated and treated Well water

\begin{tabular}{|c|c|c|c|c|c|c|c|c|c|c|c|c|}
\hline $\begin{array}{c}\text { No. of } \\
\text { Analysis }\end{array}$ & $\begin{array}{c}\mathrm{Ca} \\
(\mathrm{mg} / \mathrm{L})\end{array}$ & SD & $\begin{array}{c}\mathbf{C d} \\
(\mathrm{mg} / \mathrm{L})\end{array}$ & SD & $\begin{array}{l}\mathrm{Cu} \\
(\mathrm{mg} / \mathrm{L})\end{array}$ & SD & $\begin{array}{c}\mathrm{Fe} \\
(\mathrm{mg} / \mathrm{L})\end{array}$ & SD & $\begin{array}{c}\mathbf{M g} \\
(\mathbf{m g} / \mathbf{L} \\
)\end{array}$ & SD & $\begin{array}{c}\text { Mn } \\
\text { (mg/ } \\
\text { L) }\end{array}$ & SD \\
\hline & \multicolumn{12}{|c|}{ Before Treatment } \\
\hline 1 & 88.80 & 0.05 & 0.03 & 0.01 & 0.01 & 0.04 & 0.15 & 0.05 & 20.23 & 0.08 & 1.41 & 0.03 \\
\hline 2 & 87.50 & 0.005 & 0.03 & 0.03 & 0.02 & 0.02 & 0.16 & 0.06 & 19.20 & 0.11 & 1.20 & 0.06 \\
\hline \multirow[t]{2}{*}{3} & 88.10 & 0.004 & 0.02 & 0.01 & 0.01 & 0.02 & 0.14 & 0.05 & 20.10 & 0.14 & 1.30 & 0.03 \\
\hline & \multicolumn{12}{|c|}{ After Treatment } \\
\hline 1 & 116.50 & 0.07 & 0.01 & 0.004 & BDL & - & 0.02 & 0.10 & 0.72 & BDL & BDL & - \\
\hline 2 & 116.20 & 0.9 & 0.01 & 0.005 & BDL & - & 0.08 & 0.02 & 20.11 & 0.56 & $\mathrm{BDL}$ & - \\
\hline 3 & 115.10 & 0.7 & 0.01 & 0.01 & BDL & - & 0.07 & 0.02 & 20.20 & 0.45 & BDL & - \\
\hline
\end{tabular}

BDL: Below detection limit

\section{Conclusion}

The treatment of As(III) from ground water using shrimp shell was investigated. The As(III) treatment system reported here is simple, easy to operate and inexpensive. The As(III) treatment system can be applied in small scale in local and non exclusive areas.

1. Welch, A. H., M. S. Lico and J. L. Hughes, 1988. Ground Water, 26, 333-347.

2. Edwards, M. J. A, 1994. Water Works Assoc., 86,

3. Morgensen, S. B., T.M Nielsen, Z. Ujang and J.C Tjell, 2001. Distribution and health risk of arsenic related to abandoned tin-mining pools in Malaysia. In: The International Water Association Conference on Water and Wastewater Management for Developing Countries, KualaLumpur, Malaysia, 110-115.
4. Rabbani, G.H., A.K Chowdhury, S.K Shaha, M. Nasir, Rabbani, 2002. Mass arsenic poisoning of ground water in Bangladesh. Global Health Council Annual Conference Abstract in Proceedings, Washington DC May 28-June 1,

5. Ali, M., S.A. Tarafder, 2003.Arsenic in drinking water and in scalp hair by EDXRF: a major recent health hazard in Bangladesh. J. Radional. Nucl. Chem., 256(2), 297.

6. Katsoyiannis, I. A. and A. I. Zouboulis, 2004. Application of biological processes for the removal of arsenic from groundwaters. Water Res. 38, 17.

7. Kim, J. and M. M. Benjamin, 2004. Modeling a novel ion exchange process for arsenic and nitrate removal. Water Res. 38, 2053.

8. Aslak E., Characterisation of chitin and a study of its acid catalysis hydrolysis, 2007. Thesis paper for PhD. Degree. Norwegian University of Science and Technology. 
9. Guibal, E., A.Larkin, T.Vincent and J. M Tobin. Platinum recovery on chitosan based sorbents. In proceedints of International biohydrometallurgy Symposium (IBS'99),San Lorenzo de EI Escorial, Madrid, Spain, 1999. June 265-276, EdAmils, R.,Ballester., Elsevier.

10. Ibrahim, H. M., M. F. Salama and H. A. EL-Banna, 1999. Shrimp's waste: Chemical composition, nutritional value and utilization. Nahrung 43(6), 418-423.

11. Seco A., C. Gabaldon, P. Marzal and Aucejo, 1999. Effect of $\mathrm{pH}$, cation concentration and sorbent concentration on cadmium and copper removalby a granular activated carbon. J. Chem. Technol. Biotechnol. 74, 911,

12. Meng, X., S. Bang and G.P. Korfiatis, 2000. Effect of silicate, sulfate and carbonate on arsenic removal by ferric chloride. Water Res.34, 1255.
13. Gao. Y., K. Lee, M. Oshima and S. Motomizu, 2000. Adsorption behavior of metal ions on cross-linked chitosan and the determination of oxoanions after pretreatment with a chitosan and the determination of oxoanions after pretreatment with chitosan column, Anal. Sci, 16, 1303.

14. Reed, B. E., R. Vaughan and L. Jiang, 2000. As(III), As(V), Hg and $\mathrm{Pb}$ removal in iron oxide impregnated activated carbon columns. J. Environ. Eng. 126, 869.

15. Boddu, V. M., K. Abburi, J. L. Talbott, E. D. Smith and R. Haasch, 2008. Removal of arsenic(III) and arsenic (V) from aqueous medium using chitosan-coated bioadsorbent. Water Res., 42, 633. 